\title{
Radiation hardness of amorphous silicon particle sensors
}

\author{
N. Wyrsch ${ }^{\mathrm{a}, *}$, C. Miazza ${ }^{\mathrm{a}}$, S. Dunand ${ }^{\mathrm{a}}$, C. Ballif ${ }^{\mathrm{a}}$, A. Shah ${ }^{\mathrm{a}}$, M. Despeisse ${ }^{\mathrm{b}}$, \\ D. Moraes ${ }^{b}$, F. Powolny ${ }^{b}$, P. Jarron ${ }^{b}$ \\ ${ }^{a}$ Institut de Microtechnique, Université de Neuchâtel, Breguet 2, CH-2000 Neuchâtel, Switzerland \\ ${ }^{\mathrm{b}} \mathrm{CERN}, \mathrm{CH}-1211$ Genève 23, Switzerland
}

Available online 24 March 2006

\begin{abstract}
Radiation tests of $32 \mu \mathrm{m}$ thick hydrogenated amorphous silicon $\mathrm{n}-\mathrm{i}-\mathrm{p}$ diodes have been performed using a high-energy $24 \mathrm{GeV}$ proton beam up to fluences of $2 \times 10^{16}$ protons $/ \mathrm{cm}^{2}$. The results are compared to irradiation of similar $1 \mu \mathrm{m}$ and $32 \mu \mathrm{m}$ thick $\mathrm{n}-\mathrm{i}-\mathrm{p}$ diodes using a proton beam of $405 \mathrm{keV}$ at a fluence of $3 \times 10^{13}$ protons $/ \mathrm{cm}^{2}$. All samples exhibited a drop of the photoconductivity and an increase in the dark leakage current under both high- and low-energy proton irradiation. An almost full recovery of the device performance was observed after a subsequent thermal annealing.
\end{abstract}

(C) 2006 Elsevier B.V. All rights reserved.

PACS: 29.40.Wk; 61.82.Fk; 73.61.Jc

Keywords: Silicon; Sensors

\section{Introduction}

Vertical integration of hydrogenated amorphous silicon (a-Si:H) diodes on top of application-specific integrated circuits (ASICs) is an interesting option for the next generation of pixelized detectors for high-energy physics experiments. These innovative sensors offer advantages in terms of radiation hardness, interconnection density, integration and cost. Recently, the authors have successfully developed such sensors, aiming at the detection of single charged particles ( $\beta$ particles and protons) at the minimum ionizing energy $[1,2]$.

Even though a-Si:H has been proven to have an excellent radiation hardness, most experiments have so far been performed in the context of testing the hardness of solar cells for space applications. In thin devices, the effects of proton [3-5], neutron [6] and photon irradiation have all very similar consequences on material and diode properties: metastable deep defects are created than can be

\footnotetext{
* Corresponding author. Tel.: +41 32718 3357; fax: +41 3271833201 . E-mail address: nicolas.wyrsch@unine.ch (N. Wyrsch).
}

annealed out. The process has been very extensively studied for light-soaking but only few experiments have been carried out in the case of irradiation.

In the present work, we first tried to investigate the limits of thick a-Si:H diodes under high-energy proton beams at the fluences that are expected for detectors in future generations of particle colliders. Similar thick diodes as well as thin ones were also degraded using low-energy proton beams and lower fluences as a means of comparison with earlier irradiation experiments published in literature [3].

\section{Experimental}

The 1.1 and $32.6 \mu \mathrm{m}$ thick diodes were deposited by very high-frequency plasma-enhanced chemical vapor deposition at $70 \mathrm{MHz}$ and $200{ }^{\circ} \mathrm{C}$ at a deposition rate of $15.6 \AA / \mathrm{s}$. Test devices (in the substrate $-\mathrm{n}-\mathrm{i}-\mathrm{p}$ configuration) were evaporated on $\mathrm{Cr}$-coated glass and the pixel area $\left(2 \times 2\right.$ or $\left.5 \times 5 \mathrm{~mm}^{2}\right)$ was defined by a patterned $\mathrm{ZnO}$ top contact. More details on the fabrication and properties of the diodes are given in $[1,2,7]$. 
Thick diodes were exposed to a beam of $24 \mathrm{GeV}$ protons with fluxes up to $3 \times 10^{13}$ protons $/\left(\mathrm{cm}^{2} \mathrm{~h}\right)$ at the CERN IRRAD1 facility. Note that this rate is about four orders of magnitude higher than the dose rate expected for the large Hardron Collider at CERN. The irradiation followed cycles of 3-4 'spills' (120 ms long periods of 'beam on' with an average fluence of $1.3 \times 10^{11}$ protons) which were periodically repeated. Diodes were kept under a reverse polarization of $300 \mathrm{~V}$ and the currents with the beam on (spill-induced current, SPIC) and off were recorded. Dark $I(V)$ characteristics of the diodes were also measured at various points of the experiment as well as after subsequent annealing steps.

Degradation under low-energy protons was performed using a Van de Graff accelerator with a beam energy of $1.07 \mathrm{MeV}$, attenuated to $405 \mathrm{keV}$ using a $12 \mu \mathrm{m}$ Al foil. Under these conditions, an implantation depth for protons of $\geqslant 1.1 \mu \mathrm{m}$ into the diode intrinsic layer was estimated using SRIM software [7]. Several thin and thick diodes were irradiated under open-circuit conditions at a fluence of $3 \times 10^{13}$ protons $/ \mathrm{cm}^{2}$. Dark and illuminated $I(V)$ characteristics, mobility-lifetime product $\mu \tau$ and drift mobility $\mu$ for electrons were measured in the initial, irradiated and annealed states.

\section{Results}

Four samples were irradiated with $24 \mathrm{GeV}$ protons up to fluences of $1.89 \times 10^{16}, 3.52 \times 10^{15}, 7 \times 10^{14}$ and $2 \times$ $10^{16}$ protons $/ \mathrm{cm}^{2}$, respectively. In all experiments, the recorded SPIC exhibited a drop by $50-70 \%$ of the initial value followed by a stabilization at fluences $\geqslant 10^{15}$ protons $/ \mathrm{cm}^{2}$. Preliminary results on the first three runs were already published in [8].

During the third irradiation run, the sample was removed from the beam, kept for $20 \mathrm{~h}$ in the dark and then irradiated again. In Fig. 1, we can observe a decrease in the SPIC by $50 \%$ from the beginning of the degradation to the interruption. The latter allowed the diode to recover to $66 \%$ of the initial value, demonstrating an interesting selfannealing effect. The dark leakage current $I_{\text {dark }}$ (cf. Fig. 2) increases for higher fluence values and then seems to saturate. A larger effect of irradiation on $I_{\text {dark }}$ is observed at lower values of the applied external field. After one year of storage (to allow the radioactivity of the sample to reach an acceptable level), $I_{\text {dark }}$ was found to be unchanged. However, most of the effect of irradiation was then reversed after an annealing of $12 \mathrm{~h}$ at $100^{\circ} \mathrm{C}$, and completely after $24 \mathrm{~h}$ at $100{ }^{\circ} \mathrm{C}$.

Thin and thick samples were also degraded using a $405 \mathrm{keV}$ proton beam at a fluence of $3 \times 10^{13}$ protons/ $\mathrm{cm}^{2}$. In the case of thin diodes, protons are passing completely through the diode while in the case of thick diodes, protons are implanted $\geqslant 1.1 \mu \mathrm{m}$ below the $\mathrm{p}-\mathrm{i}$ interface. More defect creation is expected in the latter case, as the protons are releasing all their kinetic energy within the diode.

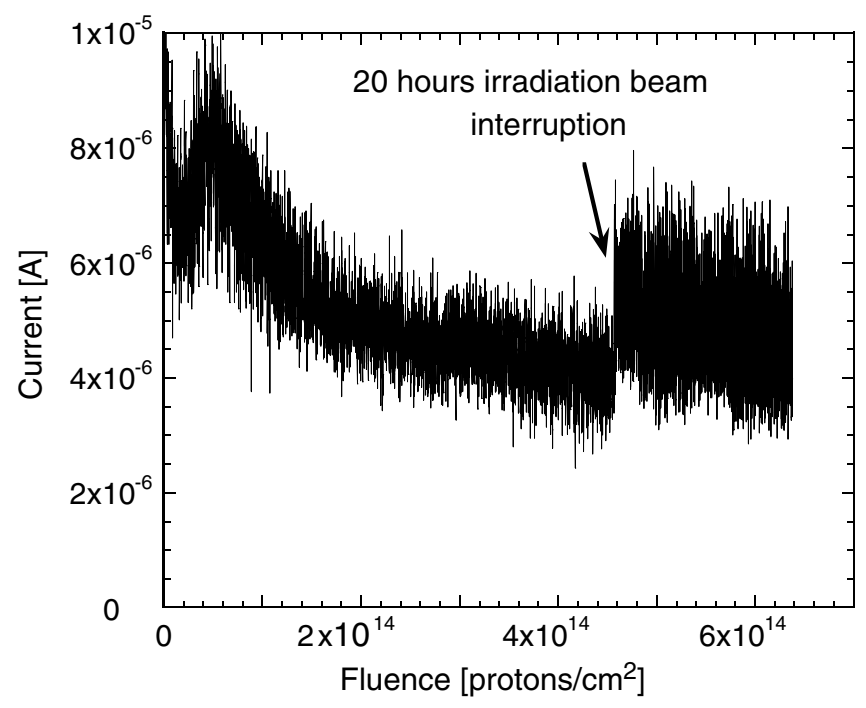

Fig. 1. Irradiation $24 \mathrm{GeV}$ protons: current induced by the proton spills (see text) on a $32.6 \mu \mathrm{m}$ a-Si:H diode as a function of proton fluence. During the beam interruption at a fluence of $4.5 \times 10^{14}$ protons $/ \mathrm{cm}^{2}$, the sample was kept under the same reverse bias voltage $(300 \mathrm{~V})$. The noise visible during the experiment originates from the variation of the beam intensity from spill to spill.

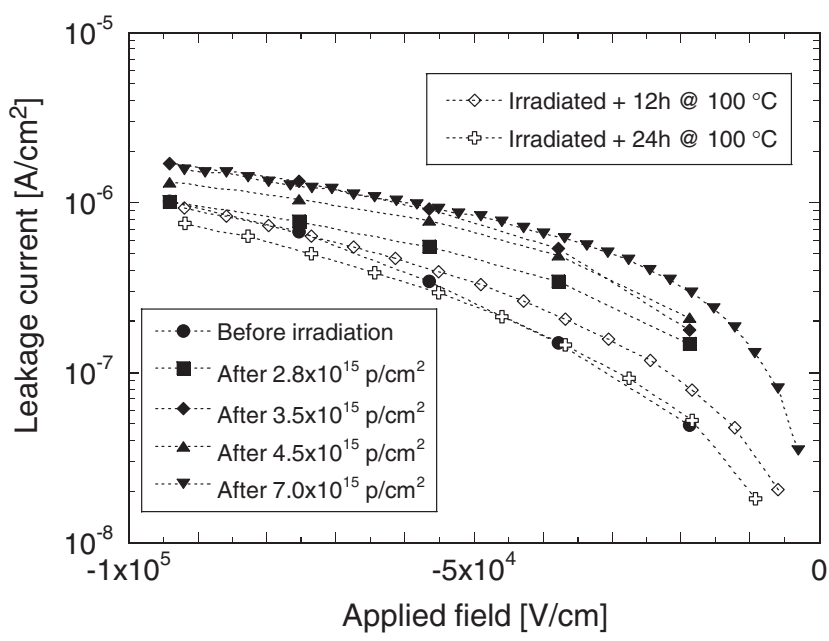

Fig. 2. Irradiation $24 \mathrm{GeV}$ protons: dark (leakage) current $I_{\text {dark }}$ as function of the applied electric field for the $32.6 \mu \mathrm{m}$ thick a-Si:H diode, in various states of irradiation with $24 \mathrm{GeV}$ protons (as plotted in Fig. 1) and annealing.

Current as a function of voltage in the dark is plotted in Fig. 3, for one thin and one thick diodes in the as deposited, irradiated, and after two steps of annealing at $180^{\circ} \mathrm{C}$. For both diodes we observe that the irradiation leads to an increase of $I_{\text {dark }}$, which is recovered to a large extend after $1.5 \mathrm{~h}$ of thermal annealing at $180^{\circ} \mathrm{C}$ and completely after $4.5 \mathrm{~h}$. The increase in $I_{\mathrm{dark}}$ is larger at lower fields where $I_{\mathrm{dark}}$ is mainly controlled by thermal generation of carriers from deep defects. At high field values, charge injection and Frenkel-Poole effects become dominant. 


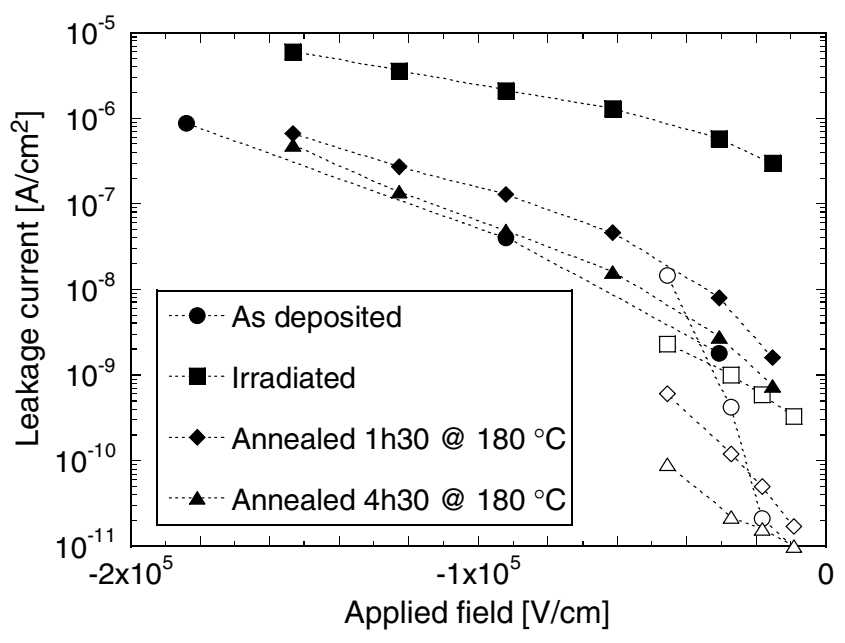

Fig. 3. Irradiation with $405 \mathrm{keV}$ protons: dark (leakage) current density $I_{\text {dark }}$ as a function of applied field for a $1.1 \mu \mathrm{m}$ thick diode (open symbols) and for a $32.6 \mu \mathrm{m}$ thick diode (full symbols) in the as-deposited, irradiated and annealed states after a $1.5 \mathrm{~h}$ at $180^{\circ} \mathrm{C}$ and after $4.5 \mathrm{~h}$ at $180^{\circ} \mathrm{C}$.

\section{Discussion}

Comparing the results of irradiation with high-energy protons (Fig. 2) and those with low-energy protons (Fig. 3), the increase in $I_{\text {dark }}$ strongly appears to depend on the density of absorbed protons and on the energy deposited locally: low-energy proton irradiation on thick diodes results in proton implantation and leads to the highest increase in $I_{\text {dark }}$ and the most pronounced creation of deep defects. In order to obtain a value for the density of created defects, charge collection experiments using TOF (time of flight) were performed. Note that these measurements could not be performed on the samples after irradiation with high-energy protons due to the radioactivity of the samples.

Values of $\mu \tau$ and $\mu$ of electrons have been analyzed for thin and thick diodes in the as-deposited, irradiated and annealed states; results are given in Table 1 . As $\mu$ is not affected by irradiation, we conclude that the change in the value of $\mu \tau$ is entirely due to a reduction in deep trapping time by creation of additional defects. The increase by one order of magnitude of the dark current after irradiation is consistent with this change in $\mu \tau$. For thick diodes, the S-shape of the collection curve for electrons (indicating a very defective region close to the p-region [9]) prevented us from extracting $\mu \tau$ values. Nevertheless, from the onset of electron collection for polarization above $150 \mathrm{~V}$ and from the proton implantation depth of $\approx 1.1 \mu \mathrm{m}$, we estimated $\mu \tau \leqslant 4 \times 10^{-9} \mathrm{~cm}^{2} / \mathrm{V}$ [8]. This value is consistent with the change in $I_{\text {dark }}$ upon irradiation. In all cases, an annealing of $1.5 \mathrm{~h}$ at $180^{\circ} \mathrm{C}$ is sufficient to recover deep defects created by the irradiation.

In order to check for the presence of additional defects affecting hole transport, $I(V)$ characteristics under white light (AM1.5) were also recorded. For the thin diode, irradiation significantly affects the illuminated $I(V)$, but the characteristics are fully recovered after annealing. No significant change of the open-circuit voltage $V_{\mathrm{oc}}$ with irradiation was observed, while fill-factor FF decreased from $\approx 55 \%$ down to less than $30 \%$ and fully recovered with annealing. In contrast, irradiation has a much more detrimental effect on the characteristics of thick diodes. The photocurrent in reverse polarization, $\mathrm{FF}$ and $V_{\mathrm{oc}}$ decreased significantly during irradiation and could not be recovered by annealing the diodes, even after $24 \mathrm{~h}$ at $180^{\circ} \mathrm{C}$. Similar observations have been made on microcrystalline silicon solar cells implanted with $405 \mathrm{keV}$ protons [10]. These observations suggest that two types of defects are involved: (a) deep defects affecting electron collection generally created by all irradiation which are easy to be annealed out and (b) probably shallower type of defects affecting hole collection induced by the proton implantation which results in an irreversible damage to the diode properties.

\section{Conclusions}

Irradiation of thick $32.6 \mu \mathrm{m}$ a-Si:H diodes with $24 \mathrm{GeV}$ protons has been compared to irradiation of $1.1 \mu \mathrm{m}$ and $32.6 \mu \mathrm{m}$ thick a-Si:H diodes with $405 \mathrm{keV}$ protons. Lowenergy protons are much more effective in creating defects, especially thin diodes, because these protons are implanted in a-Si:H intrinsic layers leading to defects that cannot be annealed out; the latter mainly affect hole collection. For this reason, the comparison of the radiation hardness of a-Si:H solar cells and of a-Si:H particle detectors is not straightforward. Nevertheless, this reduction in hole collection is not a major drawback for the detection

\section{Table 1}

Irradiation with $405 \mathrm{keV}$ protons: average mobility-lifetime products $\mu \tau$ and mobilities $\mu$ of electrons for thick and thin diodes in the as-deposited, irradiated and annealed states $\left(1.5 \mathrm{~h}\right.$ at $\left.180^{\circ} \mathrm{C}\right)$

\begin{tabular}{lllll}
\hline State & $1.1 \mu \mathrm{m}$ thick diodes & & $32.6 \mu \mathrm{m}$ thick diodes \\
\cline { 2 - 4 } & $\mu \tau\left(\mathrm{cm}^{2} \mathrm{~V}^{-1}\right)$ & $\mu\left(\mathrm{cm}^{2} \mathrm{~V}^{-1} \mathrm{~s}^{-1}\right)$ & $\mu \tau\left(\mathrm{cm}^{2} \mathrm{~V}^{-1}\right)$ & \\
\hline As deposited & $3.5 \times 10^{-8}$ & 0.28 & $1.6 \times 10^{-7}$ & 0.78 \\
Irradiated & $3.5 \times 10^{-9}$ & 0.33 & No fit possible & 0.81 \\
Annealed $(1.5 \mathrm{~h})$ & $2 \times 10^{-8}$ & 0.34 & $1.6 \times 10^{-7}$ & 0.92 \\
\hline
\end{tabular}

The relatively low value of the mobility for thin diodes is due to the large contribution of holes to collection as a consequence of the specific wavelength of $590 \mathrm{~nm}$ used for TOF measurement. 
of ionizing particles using thick a-Si:H diodes, since it is mainly the electrons that contribute to the measured current [1].

Thick a-Si:H diodes irradiated with $24 \mathrm{GeV}$ protons at fluences in excess of $10^{16}$ protons $/ \mathrm{cm}^{2}$ show a reduction in proton-beam-induced current by $\approx 70 \%$. Effects of saturation, relaxation and annealing are observed, and defects created during irradiation (as monitored by the dark current $I_{\text {dark }}$ of the diodes) can be annealed out at already $100{ }^{\circ} \mathrm{C}$. The observed high-radiation resistance is remarkable and renders a-Si:H very attractive for experiments in high-energy physics. However, supplementary data on resistance to various other particles (at different energies) and on the reversibility of the defect creation is still needed.

\section{References}

[1] P. Jarron et al., Nucl. Instrum. Methods A 518 (2004) 366

[2] N. Wyrsch et al., Phys. Status Solidi (c) 1 (2004) 1284.

[3] J. Kuendig et al., Sol. Energy Mater. Sol. Cells 79 (2003) 425.

[4] N. Kishimoto, H. Amekura, K. Kono, C.G. Lee, J. Non-Cryst. Solids 227-230 (1998) 238.

[5] R. Schwarz, J. Kolodzey, S. Aljishi, S. Wagner, R.T. Kouzes, Proc. 18th IEEE Photovolt. Special. Conf. (1985) 903.

[6] V. Perez-Mendez et al., Nucl. Instrum. Methods A 273 (1988) 127.

[7] SRIM (Stopping and Range of Ion in Matter) software. Available from: $<$ http://www.srim.org $>$.

[8] N. Wyrsch et al., MRS Proc. 862 (2005) A15.4.

[9] N. Wyrsch, A.V. Shah, J. Non-Cryst. Solids 137\&138 (1991) 431.

[10] F. Meillaud, E. Vallat-Sauvain, X. Niquille, M. Dubey, A. Shah, C. Ballif, J. Non-Cryst. Solids, these Proceedings, doi:10.1016/j.jnoncrysol.2005.11.091. 